\begin{tabular}{l} 
JOURNAL OF APPLIED SMART ELECTRICAL \\
ISAS \\
\hline
\end{tabular}

\title{
Implementasi Fuzzy Logic Controller Pada Kendali Kecepatan Sepeda
}

\author{
Bertenaga Angin \\ Angga Prasetia ${ }^{1}$, Tresna Dewi ${ }^{2}$, A. Rahman ${ }^{3}$ \\ ${ }^{1}$ Jurusan Teknik Elektro, Politeknik Negeri Sriwijaya \\ 2tresna_dewi@polsri.co.id*
}

\begin{abstract}
One alternative for environmentally friendly vehicles is wind-powered bikes. This vehicle can reduce air pollution and can be convenient in big cities. The proposed bike is equipped with a distance sensor to sense the safe proximity to nearby obstacles. If the obstacles are below a reasonable distance, the mounted buzzer is active as the warning. This bike uses the wind generated by the $8045 \mathrm{hp}$ dc rotation. The pulse-width (PWM) modulation is used to control a dc engine rotational speed with a fixed value of $155=$ low and $255=$ high. Fuzzy Logic Controller is used to increasing system effectivity to processes the input from the proximity sensor. The sufficient distance between the bike and the obstacles ahead, right and left, is set to be 1 meter. The PID controller ensures that the dc motor rotations are smooth and steady to ensure that the PWM value is still positive. In order to maintain a stable state $\mathrm{Kp}=60, \mathrm{Ki}=4.2$, and $\mathrm{Kd}=2.9$ are set as the appropriate settings for the used PID constants.
\end{abstract}

Keywords: Wind powered bicycle, pulse-width modulation (PWM), fuzzy logic, PID controller.

\begin{abstract}
Abstrak
Sepeda bertenaga angin adalah solusi dari kendaraan yang ramah lingkungan, selain dapat mengurangi polusi udara sepeda ini juga praktis untuk digunakan. Sepeda ini dilengkapai dengan sensor jarak yang digunakan sebagai pengatur jarak aman dari sepeda tersebut. Sepeda ini juga dilengkapai dengan indikator buzzer yang akan aktif apabila posisi sepeda berada dekat dengan pengendara lain. Sepeda ini digerakkan menggunakan angin yang dihasilkan oleh putaran motor dc yang telah terpasang propeller 8045. Pulse-width modulation (PWM) digunakan untuk mengatur kecepatan perputaran motor dc dengan nilai yang telah di setting sebesar $155=$ low dan $255=$ high. Logika fuzzy digunkan untuk memastikan efektifitas dalam mendeteksi halangan yang berada di depan sepeda. Dari hasil uji coba secara langsung didapat jarak efektif sepeda terhadap halangan yang berada di depan, depan sisi kanan, dan depan sisi kiri adalah 1 meter. Kontroler PID diaplikasikan untuk memastikan kelancaran dan stabilitas dari perputaran motor dc agar nilai PWM selalu stabil. Pengaturan terbaik untuk konstanta PID yang digunakan yaitu $\mathrm{Kp}=60, \mathrm{Ki}=4.2$, dan $\mathrm{Kd}=2.9$, dengan nilai tersebut sangat responsif untuk mencapai kondisi stabil.
\end{abstract}

Kata kunci: Sepeda tenaga angin, pulse-width modulation (PWM), logika fuzzy, kontroler PID.

Diterima Redaksi : 01-06-2020 | Selesai Revisi : 12-06-2020 | Diterbitkan Online : 30-06-2020

\section{Pendahuluan}

Saat ini kendaraan telah menjadi sarana transportasi yang sangat erat bagi keseharian masyarakat Indonesia.

Namun, perkembangan jumlah kendaraan di perkotaan Sepeda bertenaga angin adalah salah satu transportasi yang sangat pesat mengakibatkan peningkatan polusi yang ramah lingkungan. Sepeda ini digerakkan oleh udara yang memicu terjadinya penurunan kualitas motor yang disuplai akumulator sebagai penyedia energi kehidupan perkotaan, seperti menurunnya tingkat listrik. Energi listrik yang digunakan akan diubah kesehatan masyarakat, buruknya kualitas udara menjadi energi gerak dan diubah lagi menjadi energi perkotaan, serta memicu terjadinya global warming [1- angin. Untuk mengubah energi listrik tersebut, 2].

Global Warming memiliki kaitan erat dengan penggerak utama dari sepeda bertenaga angin ini [5-7]. penggunaan alat transportasi yang menggunakan bahan Motor dc yang digunakan dikendalikan oleh Pulse-width bakar fosil. Padahal, alat trasportasi merupakan sarana modulation (PWM) sebagai pengatur kecepatan yang paling banyak digunakan di Indonesia. Berbagai putarannya. PWM merupakan sebuah teknik modulasi dampak lingkungan yang muncul akibat aktifitas yang mengubah lebar pulsa dengan nilai frekuensi dan trasportasi tersebut telah mendorong munculnya gerakan amplitudo yang tetap. Mekanisme nilai output dari pwm 
berupa pulsa high dan low, dimana kita dapat 2.1. Desain PID Kontrol mengontrol durasi pulsa high dan low tersebut sesuai yang kita inginkan [8].

Kontroler PID diaplikasikan untuk memastikan kelancaran dan stabilitas dari perputaran motor dc agar Sepeda yang beredar di pasaran saat ini, belum ada yang nilai PWM selalu stabil [10]. Input dari PID Controller menerapkan sistem keamanan yang dapat adalah output dari fuzzy logic yang mana output dari mengendalikan kecepatan sepeda terhadap jarak fuzzy tersebut akan menjadi trigger PID Controller yang halangan ataupun jarak antara pengendara lain secara akan memberikan feedback ke inputan fuzzy tersebut otomatis, pada saat berada di jalanan yang ramai. untuk menjaga efisiensi pembacaan nilai dari sensor Dengan demikian dalam penelitian ini dibuat terhadap kecepatan perputaran motor DC. Dalam perancangan suatu sistem kendali menggunakan metode penelitian ini desain PID disimulasikan dalam Scilab. fuzzy logic untuk mengatur efektikfitas dari feedback Konstanta $\mathrm{Kp}, \mathrm{Ki}$, dan $\mathrm{Kd}$ diputuskan secara intuitif sensor terhadap putaran motor dc sebagai penunjang untuk mendapatkan respon terbaik. Gambar 2, 3, 4, dan aspek keamanan dari pengendara sepeda ini [9-15]. Dari 5 menunjukkan desain pengontrol PID. Dengan penelitian ini diharapkan sistem transportasi dapat menyesuaikan konstanta $\mathrm{Kp}$, $\mathrm{Ki}$, dan $\mathrm{Kd}$ respon terbaik digantikan menggunakan transportasi yang ramah dicapai, ditunjukkan dengan waktu transien pendek, lingkungan, demi mengurangi dampak-dampak yang overshoot kecil dan kondisi stabil. Gambar 2, 3a, 4a, dan ditimbulkan dari polusi udara.

\section{Metode Penelitian}

5a menunjukkan desain intuitif $\mathrm{Kp}, \mathrm{Ki}$, dan $\mathrm{Kd}$ untuk mendapatkan respon yang ditunjukkan oleh Gambar 2, 3b, 4b, dan 5b. Gambar 2 merupakan gain setup PID Gambar 1 menunjukkan blok diagram yang memberikan control. Pada gambar 3a konstanta disetup sebesar penjelasan secara garis besar sistem kerja dari alat $\mathrm{Kp}=70, \mathrm{Kd}=25$, dan $\mathrm{Ki}=4$ menghasilkan controller penelitian ini. Fuzzy logic digunakan untuk mengatur response pada gambar 3 b yang hasilnya masih tidak kecepatan motor DC berdasarkan switch mode dan stabil karena terdapat overshoot yang tinggi dan waktu sensor jarak yang telah ditetapkan dalam rule base. transien yang lama untuk mencapai stabil. Pada gambar Kemudian rule base tersebut diolah dalam interface 4 a konstanta disetup sebesar $\mathrm{Kp}=50, \mathrm{Ki}=2$, dan $\mathrm{Kd}=1$ engine yang kemudian menghasilkan output. Output dari menghasilkan controller response pada gambar $4 \mathrm{~b}$ yang fuzzy tersebut merupakan inputan PID Controller. PID hasilnya masih tidak stabil karena masih terdapat Controller berperan dalam mengatur efisiensi lonjakan overshoot sedangkan waktu transienya sudah pembacaan sensor jarak terhadap kecepatan perputaran lumayan cepat. Pada gambar 5a konstanta disetup motor DC sesuai set point sensor jarak yang telah $\mathrm{Kp}=60, \mathrm{Ki}=4.2$, dan $\mathrm{Kd}=2.9$ menghasilkan controller ditetapkan. Kemudian PID Controller akan menjadi response pada gambar $5 \mathrm{~b}$ yang hasilnya sangat stabil trigger driver motor untuk memicu besar kecilnya pulsa dengan waktu transien pendek serta tidak terjadi motor DC. Motor DC yang telah terhubung dengan overshoot. Akhirnya dari pengujian nilai Kp, Ki, dan Kd propeller akan berputar untuk menghasilkan tekanan yang telah dilakukan, maka dalam penelitian ini penulis angin yang berfungsi untuk mendorong sepeda [4].

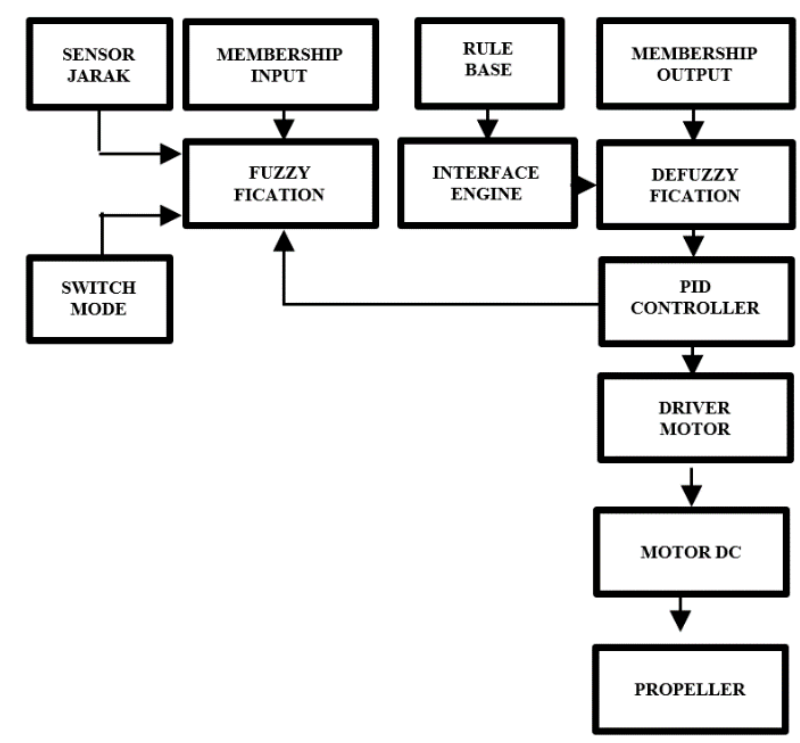
menggunakan setup nilai $\mathrm{Kp}, \mathrm{Ki}$, dan $\mathrm{Kd}$ seperti pada gambar 12 a dengan nilai $\mathrm{Kp}=60, \mathrm{Kd}=4.2$, dan $\mathrm{Ki}=2.9$.

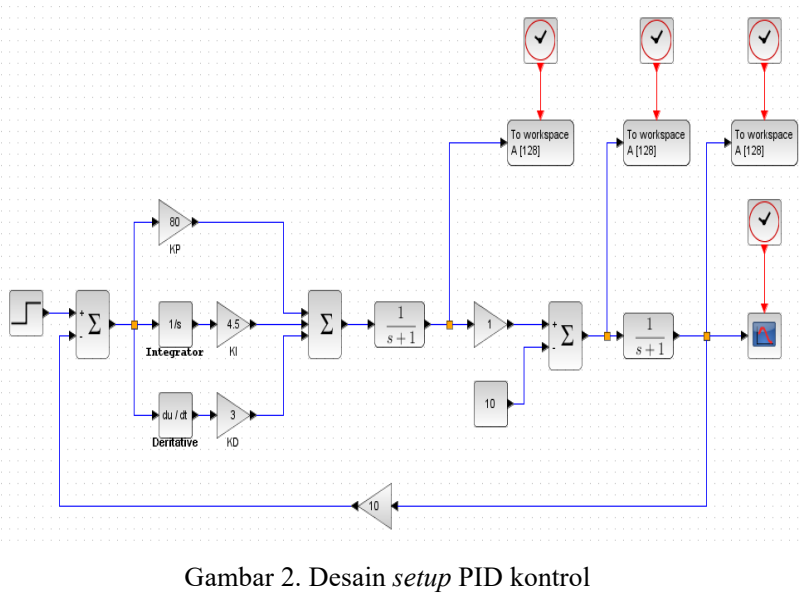

Gambar 1. Diagram skematik dari metode penelitian 


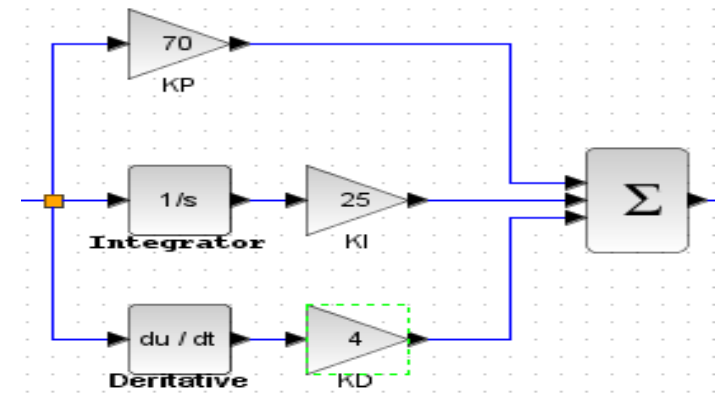

(a) Gain setup

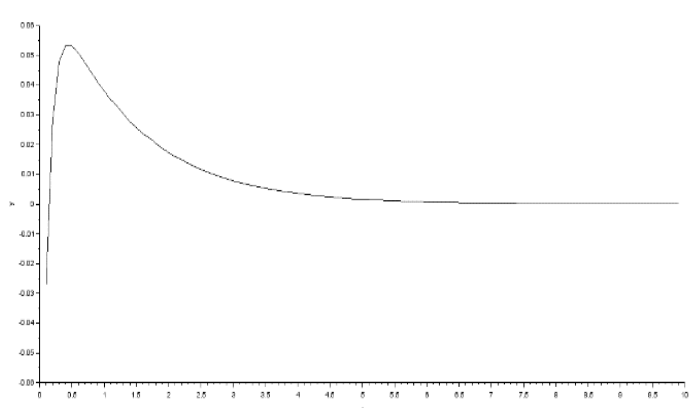

(b) Controller Response

Gambar 3. Desain setup PID kontrol dimana $\mathrm{Kp}=70, \mathrm{Ki}=25$, dan $\mathrm{Kd}=4$

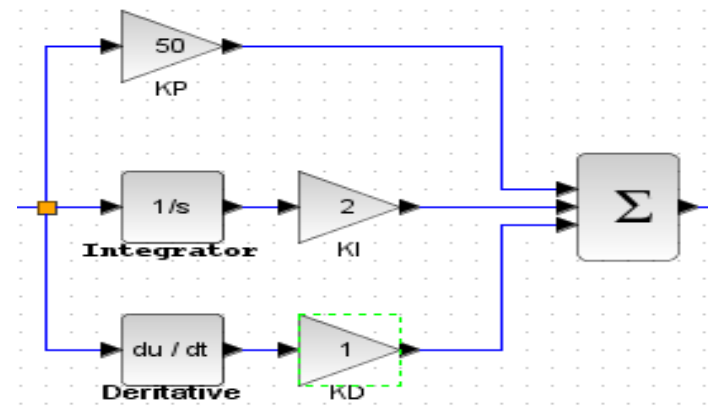

(a) Gain setup

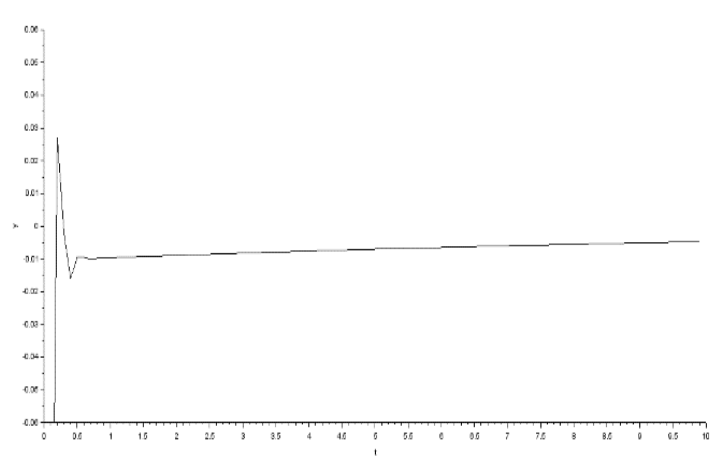

(b) Controller response

Gambar 4. Desain setup PID kontrol dimana $\mathrm{Kp}=50, \mathrm{Ki}=2$, dan $\mathrm{Kd}=1$

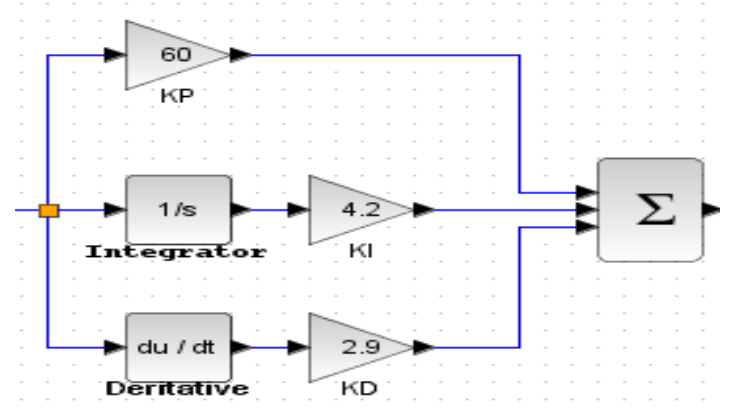

(a) Gain setup

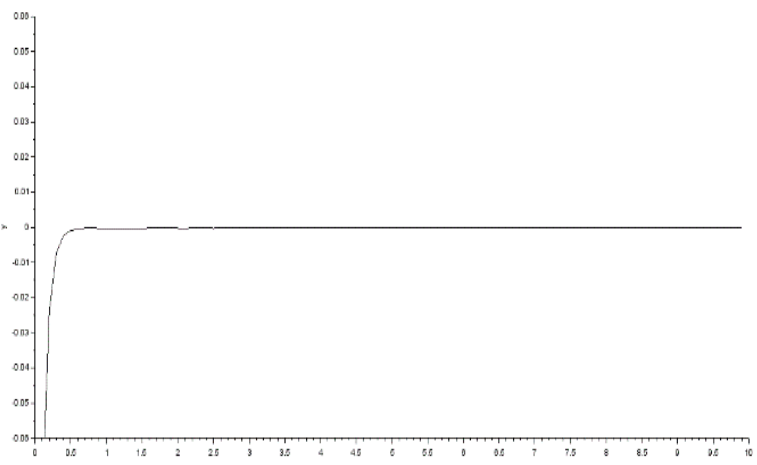

(b) Controller response

Gambar 5. Desain setup PID kontrol dimana $\mathrm{Kp}=60, \mathrm{Ki}=4.2$, dan $\mathrm{Kd}=2.9$

\subsection{Desain Mekanik}

Gambar 6,7,8 dan 9 menunjukkan desain dari sepeda bertenaga angin. Sepeda ini memiliki panjang 1.6 meter dengan tinggi 1 meter. Bagian belakang sepeda telah di desain sebuah bracket sebagai dudukan dari komponenkomponen yang digunakan seperti motor DC, accu, arduino dll. Dimensi dari bracket yang dibuat adalah $45 \mathrm{~cm}$ x $20 \mathrm{~cm}$ dengan menggunakan bahan kayu pinus. Adapun di bagian depan sepeda telah terpasang 3 sensor ultrasonik dengan posisi lurus kedeepan, $45^{\circ}$ serong kanan, dan $45^{\circ}$ serong kiri. Dibagian stang sepeda diletakkan sebuah kotak yang berisi lcd 16x2 yang akan menampilkan nilai pwm, kecepatan dari laju sepeda, dan switch mode yang digunakan untuk memilih kecepatan dari perputaran motor DC, serta tombol power yang digunakan sebagai tombol utama untuk mengaktifkan sistem sepeda ini [6]. 


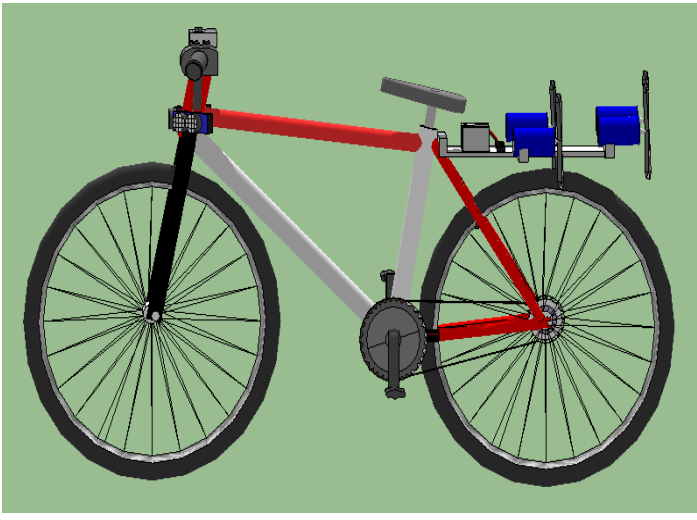

Gambar 6. Desain tampak samping

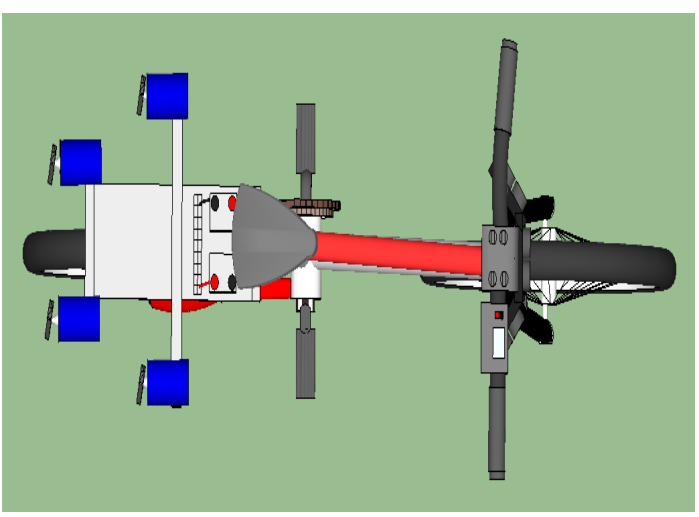

Gambar 7. Desain tampak atas

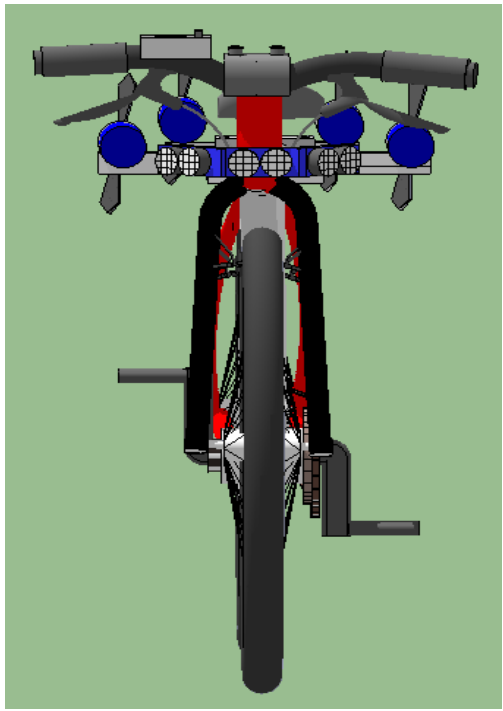

Gambar 8. Desain tampak depan

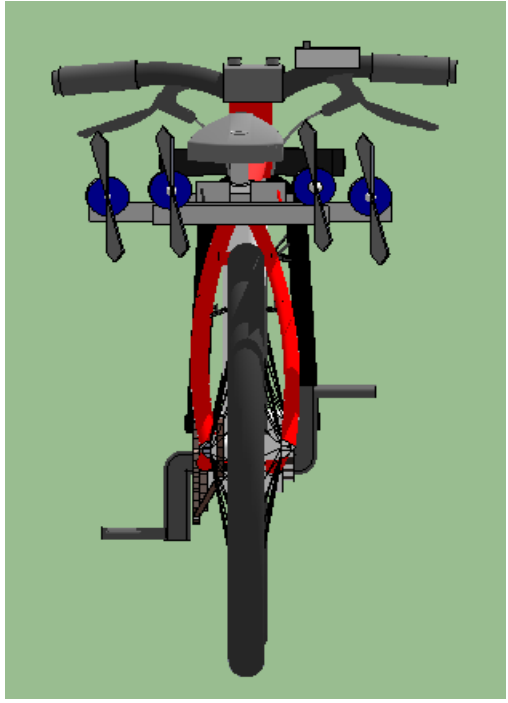

Gambar 9. Desain tampak belakang

\subsection{Desain Elektrik}

Gambar 10 menunjukkan desain elektrik dari sepeda bertenaga angin. Desain terdiri dari 2 buah accu, 1 buah arduino mega 2560, 4 buah driver motor BTS 7960, 4 buah motor brushless, 4 buah propeller 8045, 3 buah sensor ultrasonik, 1 buah buzzer, 1 buah transformator step down LM2596 serta komponen-komponen pendukung lainnya. Adapun fungsi dari masing-masing komponen yaitu, accu yang disusun secara seri sehingga menghasilkan tegangan 24V DC yang digunakan sebagai sumber energi utama dari sepeda bertenaga angin ini, arduino yang digunakan sebagai pemroses program, driver motor sebagai pengatur kecepatan motor DC, motor brushless yang digunakan sebagai sumber tenaga penghasil energi gerak yang dipadukan bersama propeller 8045 sehingga mengghasilkan energi angin, sensor untrasonik yang digunakan untuk mendeteksi jarak, buzzer yang digunkaan sebagai indikator aman atau bahaya posisi sepeda terhadap halangan, serta transformator step down yang digunakan untuk menurunkan tegangan dari $24 \mathrm{~V}$ DC menjadi $5 \mathrm{~V}$ DC dengan tujuan untuk mensuplai arduino serta sensor yang hanya dapat disuplai dengan tegangan 5V DC [6] [12] [13] [14] [15] [16].

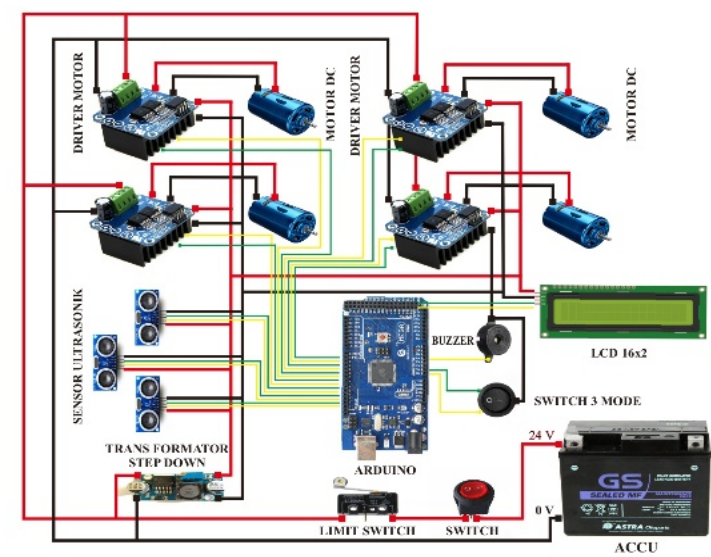

Gambar 10. Desain elektrik 


\section{Hasil dan Pembahasan}

\subsection{Desain Kontrol Logika Fuzzy}

Logika Fuzzy adalah suatu cara yang tepat untuk $1 \mathrm{~m}$, maka besarnya nilai pwm motor DC adalah low (set memetakan suatu ruang input ke dalam ruang output [9] pwm=0) dan buzzer akan aktif (high). Ketika switch [17]. Untuk sistem yang sangat rumit, penggunaan mode 2 yang aktif maka besarnya nilai pwm dari motor logika fuzzy (fuzzy logic) adalah salah satu DC adalah high (set pwm=255) dengan ketentuan ketiga pemecahannya. Sistem tradisional dirancang untuk sensor jarak mebaca jarak halangan lebih dari $1 \mathrm{~m}$. mengontrol keluaran tunggal yang berasal dari beberapa Namun jika salah satu atau ketiga sensor jarak membaca masukan yang tidak saling berhubungan. Karena jarak halangan kurang dari 1m, maka besarnya nilai ketidaktergantungan ini, penambahan masukan yang pwm motor DC adalah low (set pwm=0) dan buzzer akan baru akan memperumit proses kontrol dan aktif(high).

membutuhkan proses perhitungan kembali dari semua fungsi . Kebalikannya, penambahan masukan baru pada sistem fuzzy, yaitu sistem yang bekerja berdasarkan prinsip-prinsip logika fuzzy, hanya membutuhkan penambahan fungsi keanggotaan yang baru dan aturanaturan yang berhubungan dengannya [6] [9].

Sistem fuzzy pertama kali deperkenalkan oleh Prof. L.A. Zadeh dari Barkelay pada tahun 1965. Sistem fuzzy merupakan penduga numerik yang terstruktur dan dinamis. Sistem ini memiliki kemampuan untuk mengembangkan sistem inteligen dalam lingkungan yang tidak pasti. Sistem ini menduga suatu fungsi dengan logika fuzzy. Dalam logika fuzzy terdapat beberapa proses yaitu penentuan himpunan fuzzy, penerapan aturan IF-THEN dan proses inferensi fuzzy [6].

Tabel 1. Rule base fuzzy logic sepeda bertenaga angin

\begin{tabular}{|c|c|c|c|c|c|c|}
\hline \multicolumn{5}{|c|}{ Input } & \multirow{2}{*}{\multicolumn{2}{|c|}{ Output }} \\
\hline \multicolumn{2}{|c|}{ Switch } & \multicolumn{3}{|c|}{ Proximity Sensor } & & \\
\hline 1 & 2 & Left & Mid & Right & PWM & Buzzer \\
\hline High & Low & $\begin{array}{c}\text { Warni } \\
\text { ng }\end{array}$ & $\begin{array}{c}\text { Warni } \\
\text { ng }\end{array}$ & Warning & Low & High \\
\hline High & Low & $\begin{array}{c}\text { Warni } \\
\text { ng }\end{array}$ & $\begin{array}{c}\text { Warni } \\
\text { ng }\end{array}$ & Safe & Low & High \\
\hline High & Low & $\begin{array}{c}\text { Warni } \\
\text { ng }\end{array}$ & Safe & Safe & Medium & High \\
\hline High & Low & $\begin{array}{c}\text { Warni } \\
\text { ng }\end{array}$ & Safe & Warning & Medium & High \\
\hline High & Low & $\begin{array}{l}\text { Safe } \\
\end{array}$ & Safe & Safe & Medium & Low \\
\hline High & Low & Safe & $\begin{array}{c}\text { Warni } \\
\text { ng }\end{array}$ & Warning & Low & High \\
\hline High & Low & Safe & Safe & Warning & Medium & High \\
\hline High & Low & Safe & $\begin{array}{c}\text { Warni } \\
\text { ng }\end{array}$ & Safe & Low & Low \\
\hline Low & High & $\begin{array}{c}\text { Warni } \\
\text { ng }\end{array}$ & $\begin{array}{c}\text { Warni } \\
\text { ng }\end{array}$ & Warning & Low & High \\
\hline Low & High & $\begin{array}{c}\text { Warni } \\
\text { ng }\end{array}$ & $\begin{array}{c}\text { Warni } \\
\text { ng }\end{array}$ & Safe & Low & High \\
\hline Low & High & $\begin{array}{c}\text { Warni } \\
\text { ng }\end{array}$ & Safe & Safe & High & High \\
\hline Low & High & $\begin{array}{c}\text { Warni } \\
\text { ng }\end{array}$ & Safe & Warning & High & High \\
\hline Low & High & Safe & $\begin{array}{l}\text { Safe } \\
\end{array}$ & Safe & High & Low \\
\hline Low & High & Safe & $\begin{array}{c}\text { Warni } \\
\text { ng }\end{array}$ & Warning & Low & High \\
\hline Low & High & Safe & Safe & Warning & High & High \\
\hline Low & High & Safe & $\begin{array}{c}\text { Warni } \\
\text { ng }\end{array}$ & Safe & Low & Low \\
\hline
\end{tabular}

Tabel 1 merupakan rule base dari fuzzy logic, dimana input dari sistem ini adalah 2 switch mode yang berfungsi sebagai penentu besarnya pulsa pwm untuk motor DC dan 3 sensor jarak yang berfungsi menjaga jarak aman sepeda dari pengendara lain di sekitarnya. Output dari sistem fuzzy logic ini adalah pwm dan buzzer. Ketika switch mode 1 yang aktif maka besarnya nilai pwm motor DC adalah medium (set pwm=127) dengan ketentuan ketiga sensor jarak mebaca jarak halangan lebih dari $1 \mathrm{~m}$. Namun jika salah satu atau ketiga sensor jarak membaca jarak halangan kurang dari
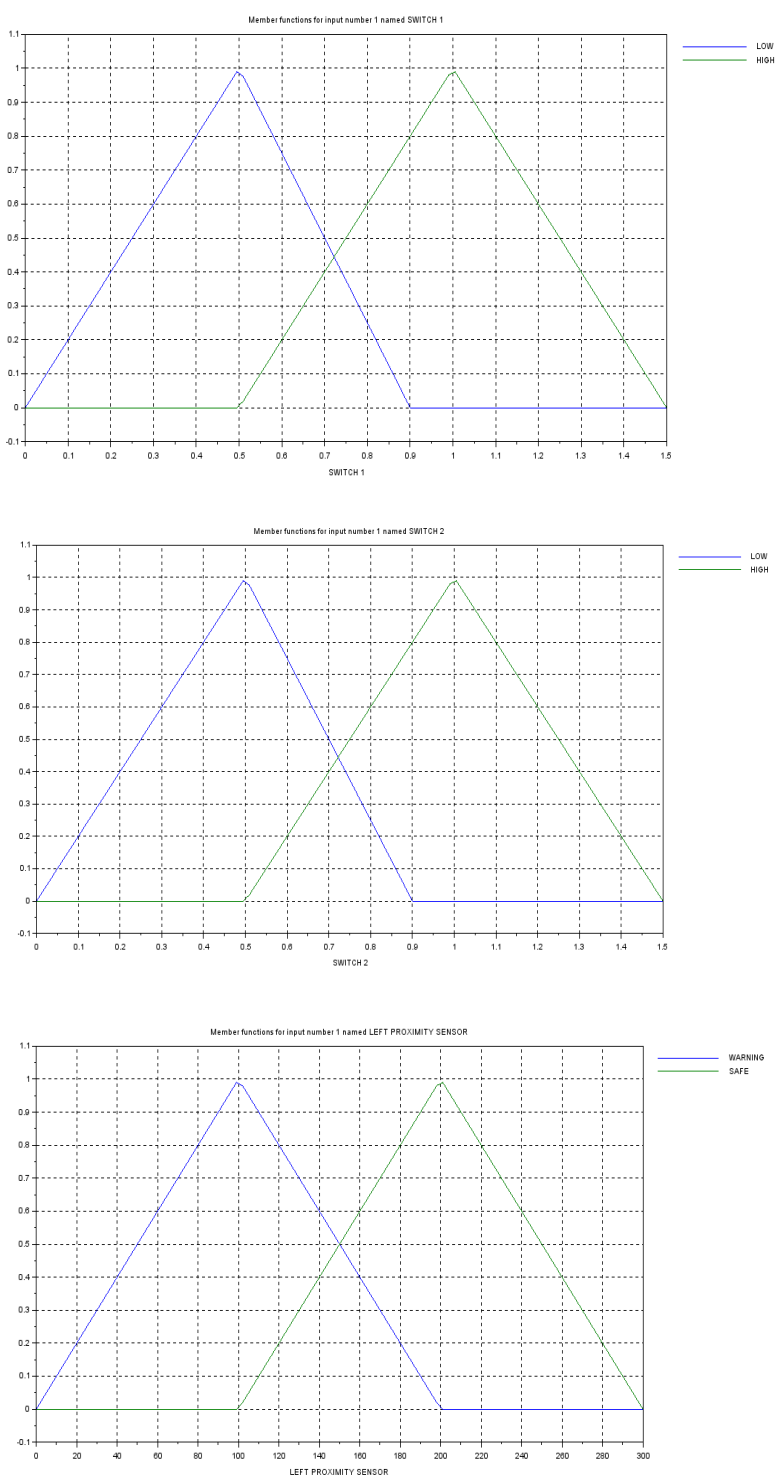

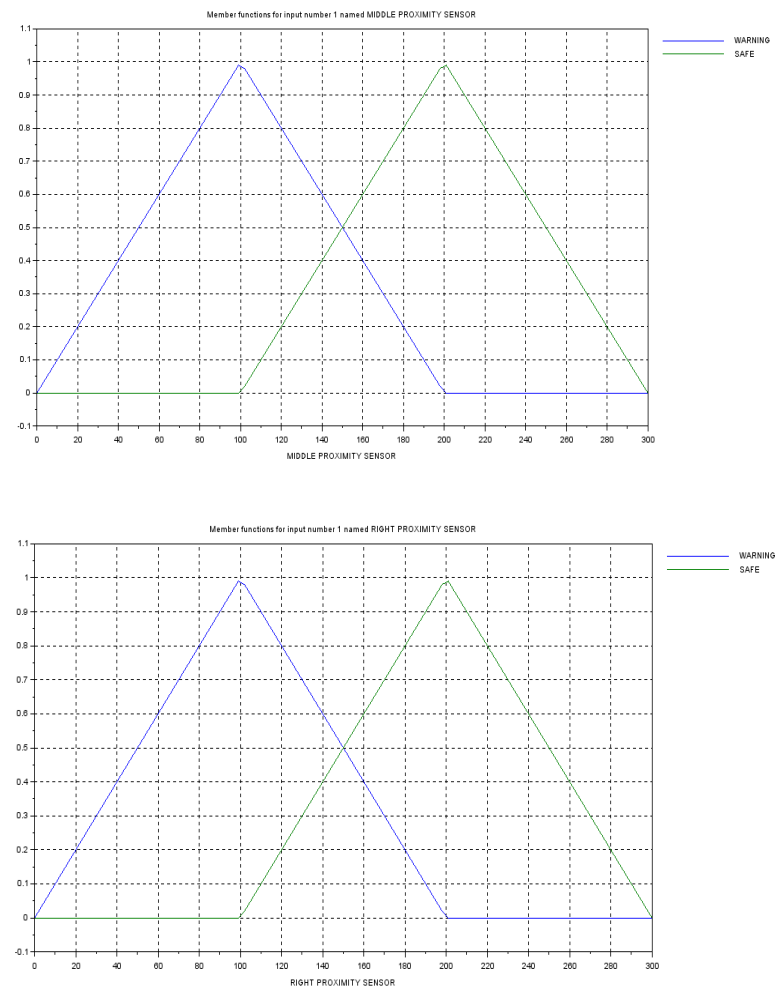

Gambar 11. Fungsi keanggotaan untuk input yang disimulasikan dengan Scilab Fungsi keanggotaan memetakan hubungan antara output menghasilkan input yang akan mengatur kecepatan
fuzzy logic dengan input. Fungsi keanggotaan yang perputaran motor DC dan output buzzer. digunakan adalah kurva sinusoidal. Gambar 11 menunjukkan fungsi keanggotaan yang memetakan input dari 3 sensor ultrasonik dan 2 switch mode. Sensor Dari penelitian ini dapat ditarik kesimpulan bahwa ultrasonik bertindak sebagai pendeteksi jarak dengan logika fuzzy memutuskan kecepatan perputaran motor range Warning (<= 1 meter) dan Safe ( $>1$ meter). DC berdasarkan deteksi jarak. Membership input dan Sedangkan 2 switch mode bertindak sebagai pemilih output fuzzy disimulasikan dengan Scilab. Penentuan kecepatan perputaran motor DC dengan indikasi input konstanta PID kontrol disimulasikan di Scilab untuk High dan Low.

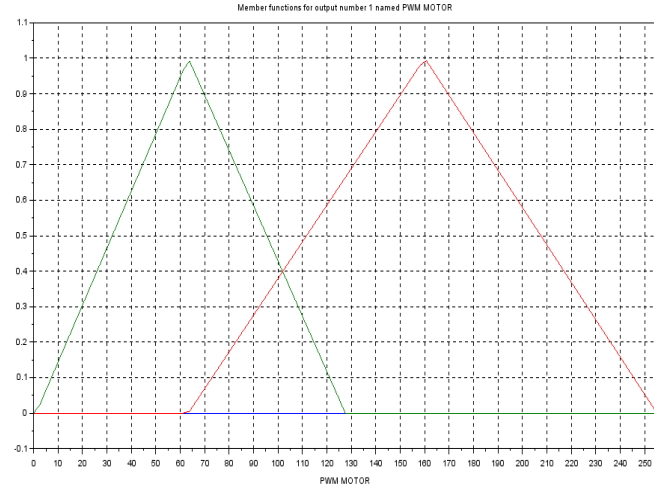

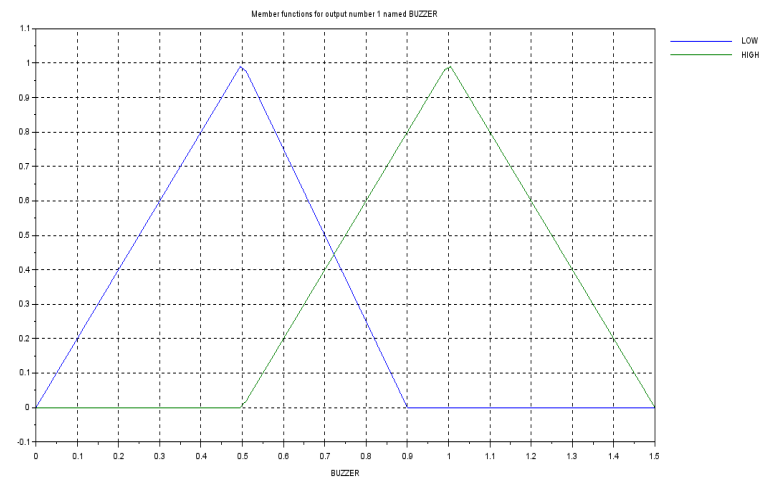

Gambar 12. Fungsi keanggotaan untuk output yang disimulasikan dengan Scilab

Output ini terhubung ke perputaran motor DC dan buzzer. Set keluaran dari Perputaran motor DC yaitu Low $(\mathrm{PWM}=0)$, Medium (PWM = 127), dan High $(\mathrm{PWM}=255)$. Sedangkan set keluaran dari buzzer yaitu High (logika $1=$ buzzer aktif $)$ dan Low $(\operatorname{logika} 0=$ buzzer non-aktif).

Logika fuzzy yang diterapkan pada penelitian ini dirancang untuk memberikan feedback dari sensor dan switch mode terhadap kecepatan perputaran motor DC dan output buzzer. Apabila salah satu switch mode aktif, dan sensor mendeteksi jarak tertentu, maka interface engine akan menentukan defuzzyfikasion, sehingga

\section{Kesimpulan} melihat waktu transien serta overshoot yang terjadi sebelum mencapai kondisi stabil, adapun konstanta yang paling efektif dari beberapa percobaan yang dilakukan adalah $\mathrm{Kp}=60 \mathrm{Ki}=4.2 \mathrm{Kd}=2.9$. Kontrol PID dikombinasikan dengan logika fuzzy untuk memastikan kelancaran, stabilitas, serta efektifitas perputaran motor DC. Dengan penambahan sistem ini, sepeda dapat melaju dengan akumulasi tekanan angin dari perputaran motor DC yang terhubung dengan propeller. Alat ini dapat diterapkan dalam masyarakat sebagai transportasi bebas polusi. Namun dalam penelitian ini belum sepenuhnya sempurna, masih banyak yang harus dikembangkan seperti safety pada propeller dan lainnya, yang saya harap dapat dikembangkan lagi oleh penelitipeneliti selanjutnya.

\section{Daftar Rujukan}

[1] LI V. O., Han Y., Lam CK. J., Zhu Y., and Bacon-Shone J., 2018, Air Pollution and Environmental in Justice: Are the Socially Deprived Exposed to More PM2.5 Polution in Hong Kong, Environmental Science \& Policy, 80, pp. 53-61. https://doi.org/10.1016/i.envsci.2017.10.014

[2] Ismiyati, Marlita D., and Saidah D., 2014, Pencemaran Udara Akibat Emisi, Jurnal Manajemen Transportasi \& Logistik (JMTransLog), 1(3), pp. 241-247. 
[3] Bactiar V. S., Raharjo S., Ruslinda Y., Hayati F., and Komala D. R., 2015, Mapping of Ozone Gas $\left(\mathrm{O}_{3}\right)$ Concentration in Padang City, Procedia Engineering, 125, pp. 291-297. https://doi.org/10.1016/i.proeng.2015.11.046.

[4] Mei H., Xiaobao Y., and Bin J., 2013, Crossing Reliability of Electric Bike Riders at Urban Intersections, Mathematical Problems in Engineering, Article ID 108636, 8 pages, https://doi.org/10.1155/2013/108636.

[5] Zhang Z., 2015, Applying Pulse Width Modulation in Body Coupled Communication, Hindawi, Article ID 378054, 6 pages. https://doi.org/10.1155/2015/378054.

[6] Sahib M. A., Ahmed B. S., and Potrus M. Y., 2014, Application of Combinatorial Interaction Design for DC Servomotor PID Controller Tuning, Hindawi, Article ID 576868, 7 pages. https://doi.org/10.1155/2014/576868

[7] Xie W., Wang J., and Wang H., 2019. PI Controller of Speed Regulation of Brushless DC Motor Based on Particle Swarm Optimization Algorithm with Improved Inertia Weights, Hindawi, Article ID 2671792, 12 pages. https://doi.org/10.1155/2019/2671792.

[8] Šlapák V., Kyslan K., Lacko M., Fedák V., and Durovský F., 2016, Finite Control Set Model Predictive Speed Control of a DC Motor, Hindawi, Article ID 9571972, 10 pages. https://doi.org/10.1155/2016/9571972

[9] Dewi T., Wijanarko Y., Risma P., and Oktarina Y., 2018, Fuzzy Logic Controller Design for Leader-Follower Robot Navigation, 5th Proc EECSI. 16-18 Oct. 2018. Malang: Indonesia. doi:10.1109/EECSI.2018.8752696.
10]Dewi T., Risma P., and Oktarina Y., 2018, Fuzzy Logic Simulation as a Teaching-learning Media for Artificial Intelligence Class, Journal of Automation Mobile Robotics and Intelligent Systems, 12(3), pp. 3-9. DOI10.14313/JAMRIS 32018/13

11] Nurmaini S., Tutuko B., Dewi K., Yuliza V., and Dewi T., 2017, Improving Posture Accuracy of Non-holonomic Mobile Robot system with Variable Universe of Discourse, TELKOMNIKA, 15(3). Pp. 1265-1279. 10.12928/TELKOMNIKA.v15i3.6078.

[12]Dewi T., Nurmaini S., Risma P., Oktarina Y., and Roriz M., 2019, Inverse Kinematic Analysis of 4 DOF Pick and Place Arm Robot Manipulator using Fuzzy Logic Controller, IJECE, 10(2), pp. 1376-1386. doi:10.11591/ijece.v10i2.pp1376-1386.

[13] Oktarina Y., Dewi T., and Risma T., 2020, The Concept of Automatic Transport System Utilizing Weight Sensor, 9(2), pp. 155-163.

14] Yudha H. M., Dewi T., Hasana N., Risma P., Oktarina, Y. Kartini S., 2019, Performance Comparison of Fuzzy Logic and Neural Network Design for Mobile Robot Navigation, Proc 2019 ICECOS, 2-3 Oct. 2019, Batam Island: Indonesia. doi: 10.1109/ICECOS47637.2019.8984577

15] Dewi T., Sitompul C., Risma P., Oktarina Y., Jelista R., Mulyati M., 2019, Simulation Analysis of Formation Control Design of Leader-Follower Robot Using Logic Controller, Proc 2019 ICECOS, 2-3 Oct. 2019, Batam Island: Indonesia. doi: $\underline{10.1109 / \text { ICECOS47637.2019.8984433 }}$ 